\title{
Cervicalcytopathology: Evaluation of its Efficacy in Detecting Cervical Precancerous and Cancerous Lesions, As Evidenced by Colposcopic Biopsy
}

\author{
Dr. T. Shobha ${ }^{1}$, Dr. Sindhuma Davuluri ${ }^{2}$ \\ ${ }^{1}$ Associate Professor Modern Government Maternity Hospital, Petlaburz, Department Of obstetrics and Gynaecology, Osmania Medical \\ College, Hyderabad - Telangana, India \\ ${ }^{2}$ Consultant, Department of Obstetrics and Gynaecology,Health Hospitals, Tenali. A.P, India
}

\begin{abstract}
Aim: To correlate the cytological findings with that of the histopathological findings in preinvasive and invasive cancerous lesions of the cervix and to assess the accuracy of the paptest as a screening procedure for cervical cancer. Materials and Methods : The present study was conducted at MAHARAJAH's INSTITUTE OF MEDICAL SCIENCES, in the Outpatient department of OBSTETRICS AND GYNAECOLOGY, over a period of 2 years, from JUNE 2010 - JULY 2012. Results: Of the 500 subjects studied, biopsy was normal in 394 (78.8\%) women i.e, they had either an inflammatory smear or a normal smear.106 women (21.2\%) had a positive biopsy, i.e., they had a premalignant or malignant lesion on biopsy. Of those with the disease,67 women had CIN I. (13.4\%),19 women had CIN II (3.8\%),20 women had malignancy on biopsy.(4\%) Conclusion: Even though the sensitivity of pap seems to be low, this can be overcome by a regular programme of papsmear screening with appropriate follow up. The regimen of repeated cytologic screenings, and follow up of abnormal results not only increases the sensitivity of Pap smear but also decreases the incidence of cervical cancer. Papsmear is an often cited example of a successful program of secondary prevention. Pap smear, a relatively simple and inexpensive procedure, is still the initial step of cervical cancer screening of women.
\end{abstract}

Keywords: Cervical Precancerous, Cancerous Lesions, Colposcopic Biopsy. Pap Smear

\section{Introduction}

Cancer cervix, a preventable disease continues to be a cause of great concern to women's health, being associated with agonizing morbidity and high mortality. Approximately 493,100 new cases and more than 273,000 deaths occur each year, among women worldwide. All over the world cervical cancer is the second most common cancer in women, after breast cancer and in developing countries it is considered as the most fatal malignancy in women.

Incidence of cervical cancer in developed and developing countries is 83,000 and 409,000 respectively. Number of deaths due to cervical cancer in developed and developing countries are 40,000 and 234,000 respectively. In Africa, its estimated that there are 36,900 new cases each year. In South Africa $32.7 \%$ of all cancers are seen in black women.

India, which accounts for one sixth of the World's population also bears one fifth of the World's burden of cervical cancer. It is the most common cancer among women in India. There are approximately 130,000 new cases of cervical cancer in India per year and the disease is reported to be responsible for almost $20 \%$ of all female deaths.

India's cervical cancer age standardized incidence rate $(30.7 / 100,000)$ and age standardised mortality rate $(17.4 / 100,000)$ are the highest in South Central Asia. Data from Mumbai, suggest that there may have been a slight decline in cervical cancer incidence in recent years. However the absolute incidence is still very high especially in rural areas where cancer cervix accounts for more than half of cancers among women and the number of cases grows due to high population rate.

Simultaneously, there is also evidence that India is on the verge of a HIV epidemic. The Indian National Aids Control Organisation estimates that the number of people living with $\mathrm{HIV}$ is approximately 5.1 million (38\% of whom were women). This suggests cause for concern given the strong association between HIV and HPV infections and evidence of more rapid progression of HPV infections to cervical neoplasia in HIV infected women.

Global evidence demonstrates that the key to reducing cervical cancer morbidity and mortality is early detection coupled with timely treatment of cervical pre cancerous lesions. Cervical cytology, often referred to as Pap smear, is perhaps the most well known of available screening methods.

Cytological screening was recommended as part of routine medical examination in gynaecological practice in context of health maintenance program, with the set goal of health for all by 2000 A.D.

Developed countries like USA have witnessed a marked decline in the incidence of invasive cancer from 44 cases/100,000 in 1947 to fewer than 8/100,000 in 2002. Much of the credit for this decline goes to detection of pre invasive disease, by organised Pap smear Screening Program.

While evidence of effective screening programs can be seen throughout the developed World, the burden and impact of 


\section{International Journal of Science and Research (IJSR) \\ ISSN (Online): 2319-7064}

Index Copernicus Value (2013): 6.14 | Impact Factor (2015): 6.391

the disease remains high in developing countries where $85 \%$ of disease related deaths occur.

Similar screening program was introduced in India in the 1950s. Cytological services in India are still a luxury. Though in existence for over half a century, these services are not even touching the fringe of the problem that they are meant to solve, namely the problem of cancer cervix. Although performing a Pap test may seem relatively simple, from both a clinical and programmatic perspective, a large number of steps are required to take an adequate smear, process and analyse the specimen and inform patients of results. If any of these steps are unreliable or logistically burdensome, the entire screening program could break down and with it, the potential for any public health benefit. Unfortunately many, if not all of these steps can be problematic in many developing countries. For example, whatever cytology screening services that do exist in such resource limited settings are usually offered in urban settings, by a small private sector or at referral centres. And even in these settings, trained cytotechnicians and cytopathologists are scarce and turn around times for processing and reading specimens are slow. Such screening programmes requires systems for transportations, communications and follow up that are beyond the capacity of health care infrastructure in most less developed countries. Lack of political will, poor organisational backup, financial constrains and priority given to other health issues like population explosions, ignorance of masses about the diseases and consequences are other important reasons for setback.

This lead to a gloomy picture that today India bears $18 \%$ of the burden of invasive cancer cervix in the world and 80$85 \%$ of the cases are detected in advanced stage III and IV, when it is too late for treatment.

WHO states that cancer cervix is a totally preventable disease. Preventable but not prevented is the glaring reality in India. Given this reality and the fact that screening by Pap smear (cytological) does have pitfalls and the fact that burden of disease is highest in low resource settings, if screening and subsequent treatment is to have a measurable affect on the burden of disease borne by women and the health care systems, a regular screening with Pap smear and proper follow up is the best approach.

The present study was undertaken to assess the sensitivity and specificity of Pap smear in picking up pre-invasive or invasive cancer in an abnormal cervix by taking the histopathology as the reference standard.

\section{Materials and Methods}

\section{Source of Data}

The present study was conducted at MAHARAJAH's INSTITUTE OF MEDICAL SCIENCES, in the Outpatient department of OBSTETRICS AND GYNAECOLOGY, over a period of 2 years, from JUNE 2010 - JULY 2012. The patients for the study were consenting women, according to the inclusion and exclusion criteria.

\section{Sample Size}

The study includes 500 women.

\section{Study Design}

It is a hospital based prospective analytical study, conducted on 500 gynaecological patients, to evaluate and compare Papsmear with cervical biopsy.

All the women falling into the eligible group were subjected to papsmear by the conventional technique, using an Ayres's spatula, following which a cervical biopsy was taken from the aceto white and abnormal areas on colposcopy, with a punch biopsy foreceps.

Both the test samples were sent to the pathology lab for reporting.

\section{Inclusion Criteria}

1) Women with abnormal vaginal discharge.

2) Women with menstrual abnormalities

3) Women with complaints like contact bleeding, or bleeding on straining or post coital bleeding.

4) Women with intermenstrual bleeding.

5) Women with postmenopausal bleeding.

6) Women with erosion of the cervix on per speculum examination.

7) Women with cervical polyps, nabothian follicles on speculum examination.

\section{Exclusion Criteria}

1) Already established case of carcinoma cervix.

2) Presence of evident growth.

3) Bleeding per vaginum.

4) Pregnant women.

5) Women with post hysterectomy status.

6) Women with previous history of treatment for cervical carcinoma.

\section{Method of Collection}

After taking a detailed history with all the pertinent information regarding patient profile in terms of Age, Age at marriage, Age at first child birth, Parity, Contraceptive use, Smoking habbits and after taking her consent, the specimen was collected after examination.

1) Patient was put in dorsal lithotomy position.

2) An unaided visual inspection of the cervix was performed under good illumination \& the squamocolumnar junction visualized.

3) No vaginal examination or application of the lubricant should be performed prior to obtaining the sample.

4) This is followed by taking a papsmear using a wooden Ayre's spatula. The pointed end of the Ayre's spatula was inserted into the cervical os in a nulliparous cervix and the rounded end of the spatula inserted into the patulous os of a parous woman.

5) The Ayre's spatula was then rotated 360 degrees around the entire ectocervix while maintaining tight contact with the ectocervical surface. The surface cells are gently scraped from the transformation zone, squamo columnar junction and the endocervical canal.

6) The specimen was then transferred to a glass slide, which was immediately placed in a bottle of $95 \%$ 


\section{International Journal of Science and Research (IJSR) \\ ISSN (Online): 2319-7064 \\ Index Copernicus Value (2013): 6.14 | Impact Factor (2015): 6.391}

ethanol fixative and transported to the laboratory, where the smears were stained by papanicolaou stain

7) Papanicolaou stain results in well stained nuclear chromatin, differential cytoplasmic counterstaining and cytoplasmic transparency.

8) The mucus is first swabbed off with cotton swabs moistened with normal saline. the cervix and vagina are then thoroughly moistened with normal saline in order to view the vascular patterns. $3 \%$ acetic acid is applied with a cotton swab and waited for 2-3 minutes. Under Colposcopic guidance the acetowhite areas and the most suspicious areas were then biopsied.

9) The tissue obtained was fixed by $10 \%$ formalin and sent to the lab where it was stained with Eosin and Hematoxylin.

\section{Reporting}

Cytology was reported by the pathologist as per the Bethesda III system and the histopathology was reported in the CIN system.

\section{Threshold for Positivity}

Cytology was considered positive if it showed LSIL or a more severe lesion.

Biopsy was considered positive if it showed CIN 1 and above.

\section{Reference standard and definition of true positive lesion} :

This study was taken up to evaluate the diagnostic accuracy of papsmear by comparing it against the gold standard or the reference standard, the biopsy. In biopsy, CIN 1, 2, 3 or higher lesions were considered as true positive.

\section{Statistical Software}

Statistical data pertaining to sensitivity, specificity and efficacy rate of cervical cytology were calculated. Statistical software namely SPSS - 11.0 and Systat 8.0 were used for the analysis of the data and Microsoft word and excel have been used to generate graphs and tables.

\section{Results}

Table 1: Age distribution of subjects

\begin{tabular}{|c|c|c|c|}
\hline $\begin{array}{c}\text { Age } \\
\text { (yrs) }\end{array}$ & $\begin{array}{c}\text { Total number } \\
\text { of Subjects }\end{array}$ & $\begin{array}{c}\text { Papsmear } \\
\text { Positive. }\end{array}$ & $\begin{array}{c}\text { Biopsy } \\
\text { Positive. }\end{array}$ \\
\hline$\leq 20$ & $8(1.6)$ & - & - \\
\hline $21-30$ & $165(33)$ & $20(22.7)$ & $24(22.6)$ \\
\hline $31-40$ & $191(38.2)$ & $15(17.04)$ & $10(9.43)$ \\
\hline $41-50$ & $104(20.8)$ & $38(43.18)$ & $57(53.77)$ \\
\hline $51-60$ & $22(4.4)$ & $10(11.36)$ & $8(7.54)$ \\
\hline$>60$ & $10(2)$ & $5(5.68)$ & $7(6.60)$ \\
\hline Total & 500 & 88 & 106 \\
\hline
\end{tabular}

(Figures in parenthesis indicate percentage.)

The above table shows the age distribution of the subjects studied.

Maximum number of subjects were in the age group of 3140 yrs $(38.2 \%)$.
$53.7 \%$ of positive cases were detected in women of $41-50 \mathrm{yrs}$ age.

Mean age of the study group was $38.41 \pm 9.92$

Statistical analysis shows that the incidence of precancerous or cancerous lesions in women $>40$ yrs was almost twice its incidence in younger women.

Table 2: Age at Marriage of Subjects.

\begin{tabular}{|c|c|c|c|}
\hline $\begin{array}{c}\text { Age at } \\
\text { marriage }\end{array}$ & $\begin{array}{c}\text { Total number } \\
\text { of subjects. }\end{array}$ & $\begin{array}{c}\text { Papsmear } \\
\text { positive }\end{array}$ & $\begin{array}{c}\text { Biopsy } \\
\text { positive. }\end{array}$ \\
\hline$\leq 15$ yrs & $158(31.6)$ & $50(56.8)$ & $51(48.1)$ \\
\hline $16-20$ & $246(49.2)$ & $30(34.1)$ & $46(43.3)$ \\
\hline $21-25$ & $88(17.6)$ & $8(9.1)$ & $8(7.5)$ \\
\hline $26-30$ & $80(1.5)$ & - & $1(0.9)$ \\
\hline Total. & 500 & 88 & 106 \\
\hline
\end{tabular}

(figures in parenthesis indicate percentage.)

This table shows age at marriage of the subjects.

About 246 women were married between the ages of 16 and 20 yrs.( i.e $49.2 \%$ ).

Majority of the positive cases ( $91.4 \%$ ) were detected in women who were married at an early age $(<20 \mathrm{yrs})$.

Mean age at marriage of the study group was $16.81 \pm 3.29$

The incidence of precancerous and cancerous lesions is 1.5 times higher in women married before 20 yrs than those married at a later age.

Table 3: Distribution of Marital Life Among Subjects

\begin{tabular}{|c|c|c|c|}
\hline $\begin{array}{c}\text { Yrs of } \\
\text { marriage. }\end{array}$ & $\begin{array}{c}\text { Total number } \\
\text { of subjects }\end{array}$ & $\begin{array}{c}\text { Papsmear } \\
\text { positive. }\end{array}$ & $\begin{array}{c}\text { Biopsy } \\
\text { positive. }\end{array}$ \\
\hline $1-10$ & $140(28)$ & $9(9.7)$ & $21(20)$ \\
\hline $11-20$ & $195(39)$ & $27(31)$ & $40(38.2)$ \\
\hline $21-30$ & $125(25)$ & $30(34)$ & $29(27.1)$ \\
\hline $31-40$ & $26(5.3)$ & $12(13.5)$ & $10(9.7)$ \\
\hline $41-50$ & $12(2.4)$ & $9(9.7)$ & $5(4.4)$ \\
\hline$>51$ & $2(0.4)$ & $1(0.97)$ & $1(0.9)$ \\
\hline Total & 500 & 88 & 106 \\
\hline
\end{tabular}

(figures in parenthesis indicate percentages.)

The above table shows the distribution of marital life among the subjects. Maximum number of subjects had a marital life of 11- 20 yrs (39\%).

Mean marital life was $17.8 \pm 9.96$

Statistical analysis shows that women with marital life greater than 30 yrs had 2 times higher risk for developing precancerous cancerous lesions of the cervix.

Table 4: Parity Distribution of Subjects

\begin{tabular}{|c|c|c|c|}
\hline Parity & $\begin{array}{c}\text { Total number of } \\
\text { subjects. }\end{array}$ & Pap positive & $\begin{array}{c}\text { Biopsy } \\
\text { positive. }\end{array}$ \\
\hline Nullipara & $21(4.1)$ & $2(1.9)$ & $2(2.2)$ \\
\hline $1-2$ & $257(51.3)$ & $32(36.8)$ & $49(46.2)$ \\
\hline $3-4$ & $199(39.8)$ & $44(50)$ & $47(44.4)$ \\
\hline$>4$ & $23(4.6)$ & $10(11.6)$ & $8(7.5)$ \\
\hline Total & 500 & 88 & 106 \\
\hline
\end{tabular}

(figures in parenthesis indicate percentage) 


\section{International Journal of Science and Research (IJSR) \\ ISSN (Online): 2319-7064 \\ Index Copernicus Value (2013): 6.14 | Impact Factor (2015): 6.391}

This table shows that majority of patients were of para 1 or 2.

Highest parity in the study group was 8 .

Women with parity greater than 5 were at alomost 3 times higher risk to develop precancerous or cancerous lesions compared to nulliparas.

Table 5: Contraception Practice among Subjects

\begin{tabular}{|c|c|c|c|}
\hline $\begin{array}{c}\text { Type of } \\
\text { contraception }\end{array}$ & $\begin{array}{c}\text { Total number } \\
\text { of subjects. }\end{array}$ & Pap positive. & $\begin{array}{c}\text { Biopsy } \\
\text { positive. }\end{array}$ \\
\hline Tubectomy. & $348(69.5)$ & $55(62.1)$ & $74(70.2)$ \\
\hline OCP & $18(3.6)$ & $3(2.9)$ & $5(4.8)$ \\
\hline Condoms & $24(4.8)$ & $3(3.8)$ & $3(2.6)$ \\
\hline Vasectomy & $7(1.3)$ & - & $2(1.8)$ \\
\hline Cu-T & $5(1)$ & - & $1(0.9)$ \\
\hline None & $98(19.5)$ & $27(31)$ & $21(20)$ \\
\hline Total & 500 & 88 & 106 \\
\hline
\end{tabular}

(figures in parenthesis indicate percentage).

The above table shows that maximum number of patients included in the study were tubectomised $(69.5 \%)$. Out of 106 biopsy positive cases, only $2.6 \%$ were using barrier contraceptives and almost $97 \%$ were using other methods, all exposed to the risk of sexually transmitted diseases.

Table 6: Distribution of Cases Based on Socioeconomic Status

\begin{tabular}{|c|c|c|c|}
\hline $\begin{array}{c}\text { Socio economic } \\
\text { status }\end{array}$ & $\begin{array}{c}\text { Total number } \\
\text { of cases }\end{array}$ & Pap positive. & $\begin{array}{c}\text { Biopsy } \\
\text { positive. }\end{array}$ \\
\hline Upper & $15(3)$ & $1(1.9)$ & $1(0.94)$ \\
\hline Middle & $175(35)$ & $15(17.4)$ & $30(28)$ \\
\hline Lower & $310(62)$ & $72(81.5)$ & $75(70.6)$ \\
\hline Total & 500 & 88 & 106 \\
\hline
\end{tabular}

The table shows that maximum number of patients were from the lower socio economic status. $(62 \%)$

$81.5 \%$ of the positive cases were in women from the low socioeconomic status.

Women belonging to socio economic status were at 2.6 times higher risk to develop precancerous lesions compared to those of higher socioeconomic status.

Table 7: Distribution of symptoms among subjects

\begin{tabular}{|c|c|c|c|}
\hline Symptoms & $\begin{array}{c}\text { No of } \\
\text { subjects. }\end{array}$ & $\begin{array}{c}\text { Pap } \\
\text { positive }\end{array}$ & $\begin{array}{c}\text { Biopsy } \\
\text { positive }\end{array}$ \\
\hline WDPV & 387 & 54 & 93 \\
\hline MI & 258 & 38 & 88 \\
\hline PAIN ABDOMEN & 70 & 13 & 6 \\
\hline PCB & 23 & 9 & 14 \\
\hline
\end{tabular}

This table shows presentation of various complaints by the subjects.

White discharge was the most common complaint in the studied group $(77.4 \%)$
However, patients presenting with post coital bleeding were at higher risk for developing cervical precancerous or cancerous lesions.

Table 8: Distribution of Cases By PAP Smear

\begin{tabular}{|c|c|c|}
\hline NEGATIVE / INFLAMMATORY & 412 & $82.4 \%$ \\
\hline ASCUS & 17 & $3.3 \%$ \\
\hline LSIL & 43 & $8.6 \%$ \\
\hline HSIL & 14 & $2.7 \%$ \\
\hline MALIGNANCY & 14 & $2.8 \%$ \\
\hline TOTAL & 500 & $100 \%$ \\
\hline
\end{tabular}

All 500 patients were subjected to Papsmear test.

$82.4 \%$ of the smears were negative or inflammatory smears.

$11.9 \%$ of the smears were graded as ASCUS or LSIL.

$2.7 \%$ were reported as HSIL and $2.8 \%$ were positive for malignancy.

So, out of the 500 cases studied, 88 cases were positive on papsmear.

And 412 were either negative or had an inflammatory smear.

Table 9: Distribution of Cases By Biopsy

\begin{tabular}{|c|c|}
\hline NORMAL & $394(78.8)$ \\
\hline CIN 1 & $67(13.4)$ \\
\hline CIN 2,3 & $19(3.8)$ \\
\hline MALIGNANCY & $20(4)$ \\
\hline TOTAL & 500 \\
\hline
\end{tabular}

(Figures in parenthesis indicate percentages.)

Of the 500 subjects studied, biopsy was normal in 394 (78.8\%) women i.e, they had either an inflammatory smear or a normal smear.

106 women $(21.2 \%)$ had a positive biopsy, i.e, they had a premalignant or malignant lesion on biopsy.

Of those with the disease,

67 women had CIN I. (13.4\%)

19 women had CIN II $(3.8 \%)$

20 women had malignancy on biopsy.(4\% )

Table 10: Statistical Analysis: Correlation of PAPSMEAR and Biopsy

\begin{tabular}{|c|c|c|c|}
\hline \multirow{2}{*}{ PAPSMEAR } & \multicolumn{2}{|c|}{ BIOPSY } & \multirow{2}{*}{ Total } \\
\cline { 2 - 3 } & positive & negative & \\
\hline Positive & 68 & 20 & 88 \\
\hline Negative & 38 & 374 & 412 \\
\hline Total & 106 & 394 & 500 \\
\hline
\end{tabular}

Sensitivity of PAP Test: $64 \%$

Specificity: $95 \%$

Positive Predictive Value: $77 \%$

Negative Predictive Value: $90.7 \%$

Accuracy: $88.4 \%$

Majority of the patients had more than one complaint. 


\section{International Journal of Science and Research (IJSR) \\ ISSN (Online): 2319-7064}

Index Copernicus Value (2013): 6.14 | Impact Factor (2015): 6.391

\section{Discussion}

Table 11: Comparision of diagnostic values of papsmear of various studies

\begin{tabular}{|c|c|c|c|}
\hline Study & Sensitivity & Specificity & $\begin{array}{c}\text { Reference } \\
\text { Standard }\end{array}$ \\
\hline Goel et al (2003) & $50 \%$ & $97 \%$ & Colposcopy \\
\hline Hendrik S Cronje et al & $53.30 \%$ & $94.60 \%$ & $\begin{array}{c}\text { Colposcopy } \\
/ \text { Biopsy }\end{array}$ \\
\hline Doh et al (2001) & $47.70 \%$ & $94.20 \%$ & Biopsy \\
\hline $\begin{array}{c}\text { R.Sankaranarayanan et } \\
\text { al (multicenteric -2003) }\end{array}$ & $72.30 \%$ & $97.90 \%$ & $\begin{array}{c}\text { Colposcopy } \\
/ \text { Biopsy }\end{array}$ \\
\hline P.S. Basu et al (2003) & $29.50 \%$ & $92.30 \%$ & $\begin{array}{c}\text { Colposcopy } \\
/ \text { Biopsy }\end{array}$ \\
\hline Present study & $64 \%$ & $94.90 \%$ & $\begin{array}{c}\text { Colposcopy } \\
\text { /Biopsy }\end{array}$ \\
\hline
\end{tabular}

The risk of cervical cancer continues to be still high in many developing countries, including India, where $70 \%$ of the affected patients present late and also because screening programmes are not being routinely conducted.

In India, screening by papsmear is not being effectively conducted due to several limitations like inadequate coverage of a large population, lack of awareness and lack of proper follow up.

As a screening test pap has been foundto have a low sensitivity, between $50 \%$ and $80 \%$, thereby resulting in a high false negative rate of $9-40 \%$.the sensitivity is even lower in developing countries. The possible reason for this may be the large percentage of cervicitis and inflammatory smears, which mask mild dysplasia.

However, the specificity of cytological evaluation is high In the present study, the sensitivity of cytology is $64 \%$ and the specificity is $94.9 \%$. This is similar to the study conducted by Hendrik S Cronje et al, where the sensitivity was $53.3 \%$ and specificity was $94.6 \%$.

A study by Doh et al (2001) showed a sensitivity of $47.7 \%$ and specificity of $94.2 \%$.

A study conducted by Goel et al showed that Pap test has a sensitivity of $50 \%$ and a specificity of $97 \%$.

A multicenteric study by Sankaranarayan et al showed a sensitivity of Pap smear ranging from $36.6 \%$ to $72.3 \%$ and a specificity ranging from $87.2 \%$ to $98.6 \%$.

The sensitivity of cytological examination still continues to be a subject of debate.Other studies also varied in the sensitivity rates while the specificity rates were similar to the present study.

Higher sensitivity reported in some studies may be because of

- Variations in the quality of specimen collection

- Lower threshold for positivity of pap smear in the study.

The very low sensitivity of papsmear in some studies may be because of high percentage of inflammatory smears.
Fahey et al has reported a sensitivity of $58 \%$ and specificity of $69 \%$.

Also, unless histologic condition is determined on all the screening negatives, in addition to the screen positives, the sensitivity will be unrealistically high.This statement has been confirmed in a recent review of sensitivity of cytologic examination by Nanda et al.

So, to avoid this, all the subjects included in the study, ie, both the negatives and positives on papsmear were subjected to cervical biopsy and the biopsy was taken as the reference standard in the study.

The mean age of our study population is 34 yrs. The incidence of cervical lesions after the age of $60 \mathrm{yrs}$ was almost $7 \%$. and about $32 \%$ of the cervical precancerous or cancerous lesions occurred before the age of $40 \mathrm{yrs}$.Hence, from this data, the WHO recommendation to screen for cervical cancer before the age of $35 \mathrm{yrs}$ has been justified. Early screening is mandatory to detect premalignant lesions and to prevent incidence of cervical cancer.

The mean age at marriage of this study was $16 \mathrm{yrs}$, which is an important risk factor for cancer cervix. $51 \%$ of the subjects were married at an age less than 16 yrs.this study shows that these women are at 1.5 times higher risk for precancerous lesions compared to those married after 20 yrs of age. Early marriage is still prevalent in India particularly in the rural setup. Education and stringent laws are important to tackle this social problem

Long duration of marital life and hence, prolonged sexually active period has been implicated as a risk factor. This study has shown that women with marital life $>30$ yrs have 2 times higher risk for precancerous lesions or cancver cervix.

High parity (para 5 or more) has also shown significant association with precancer. These women are at 2.6times higher risk for precancerous lesions compared to nulliparity.

$69.5 \%$ of the patients were tubectomised and only $2.6 \%$ were using barrier contraception. The association of use of oral contraceptives with the development of cervical cancer cannot be proved because of their use for a short duration.

$81.5 \%$ of the lesions were seen in women belonging to low socio-economic status (as per the B.G Prasad classification). The reasons for this may be early age at marriage, malnutrition, multiparity, all of which are mostly predominant in the lower classes.

Eventhough white discharge is present in $77.7 \%$ of the participants, this complaint is not significantly associated with the risk of precancerous lesions compared to the history of post coital bleeding, which was significantly associated with precancerous lesions and invasive cancer. Hence, these patients should be promptly evaluated for presence of malignancy. 


\section{International Journal of Science and Research (IJSR)}

ISSN (Online): 2319-7064

Index Copernicus Value (2013): 6.14 | Impact Factor (2015): 6.391

\section{Limitations of the Study}

In this study, sample is selected from the population attending the OPD This population is not representative of the general population

Hence when this test is used for screening in general population, the estimated sensitivity and specificity may not be achievable.

\section{Summary and Conclusion}

The present study was conducted with the aim to evaluate the sensitivity, specificity, positive predictive value and negative predictive value of pap smear in detection of CIN and to evaluate its diagnostic value.

The confirmation of the true positive cases was done by cervical biopsy.

This study includes a total of 500 patients attending the OP department of Gynecology.

Patients with abnormal vaginal discharge, menstrual abnormalities and with an abnormal cervix on speculum examination were subjected to papsmear.

Simultaneously, cervical biopsy was also taken from these women.

The mean age of the study group was $34.8 \pm 9.9$ yrs.

The mean age at marriage was $16.8 \pm 3.29$ yrs.

Mean marital life was $17.8 \pm 9.96$ yrs.

Majority of the patients were para 1 or 2 .

Early age at coitus,multiparity, and low socioeconomic status have 1.5, 2.6, and 2.6 times higher risk respectively for developing precancerous or cancer cervix.hence, these are significant risk factors.

Pap test in the past was the successful cervical cancer screening programme and still continues to be. No test is $100 \%$ accurate and it is possible for the papsmear to miss the presence of cancer.However, abnormal cells missed on one test are likely to be spotted during the next test without any significant danger.

$90-95 \%$ of the false negatives of the test are due to inadequate sampling and improper slide preparation..The sensitivity can be improved by correcting these errors.

Whereas, a single test yields as much as $10-15 \%$ false negative reading, it is reduced to only $1 \%$ with 3 repeated tests.

A yearly negative pap smear for 3 years is assuring.

So, even though the sensitivity of pap seems to be low, this can be overcome by a regular programme of papsmear screening with appropriate follow up.

The regimen of repeated cytologic screenings, and follow up of abnormal results not only increases the sensitivity of Pap smear but also decreases the incidence of cervical cancer.

Papsmear is an often cited example of a successfulprogram of secondary prevention.

Pap smear, a relatively simple and inexpensive procedure, is still the initial step of cervical cancer screening of women.

\section{References}

[1] D M Christie, M Mohambal, Ramamurthy V, Sneha NB. "A Study of cervical cancer screening for Prevention of Carcinoma cervix." Journal of the Indian Medical Association. Vol. 106. Issue no. 0019-5847, dec 2008, pages 779-782.

[2] Ferlay J, Bray F, Pisani P, Parkin DM, GLOBOCAN 2000 : Cancer incidence mortality and prevalence worldwide.IARC Press,2001; version 1.0.IARC cancer base No.5

Out of the 500 patients, pap test was positive in 88 women.

Of the 106 cases positive on biopsy, pap was positive in 68 women.

[3] Cancer survival in developing countries. Sankaranarayanan R, Black RB, Parkin DM,

[4] National Cancer Registry Programme. Consolidated report of the Population-base Cancer Registries 2001-2004.

When biopsy was taken as a reference standard, Pap smear has a sensitivity of $64 \%$

Specificity of $94.9 \%$.

Positive predictive value of $77 \%$.

Negative predictive value of $90.7 \%$

Accuracy of $88.4 \%$

\section{Conclusion}

[5] RengaswamySankaranarayanan,

AtulMadhukarBudukh, \&RajamanickamRajkumar. Effective screening programmes for cervical cancer in low- and middle-income developing countries. Bulletin of the World Health Organization, 2001, 79: 954-962.

[6] H.S. Cronje, Trumpelmann MD, Divall PDJ, Scott LL, Middlecote BD, De Wet JI. Screening for cervical cancer in developing countries. International Journal of Gynaecology\& Obstetrics. Vol. 84, Issue 2, pages 101 108, febraury 2004.

[7] Jayant $\mathrm{K}$ et al. Improved stage at diagnosis of cervical cancer with increased cancer awareness in a rural Indian population. International Journal of Cancer, 1995, 63: 161-163.

[8] Dr. Debbie Saslow, Dr. Carolyn D. Runowicz, Dr. Diane Solomon, Dr. Anna-Barbara Moscicki, Dr.

No woman should be denied of this opportunity. 


\section{International Journal of Science and Research (IJSR) \\ ISSN (Online): 2319-7064}

Index Copernicus Value (2013): 6.14 | Impact Factor (2015): 6.391

Robert A. Smith, Dr. Harmon J. Eyre,Dr. Carmel Cohen. American Cancer Society Guideline for the Early Detection of Cervical Neoplasia and Cancer. CA: A Cancer Journal for Clinicians. Volume 52, Issue 6, pages 342-362,November/December 2002.

[9] Parkin DM, Pisani P, FerlayJ.Global cancer statistics.CA Cancer J.Clin 1999;49:33-64

[10] Steven R. Long, Michael B. Cohen. "Classics in cytology VI: The Early Cytologic Discoveries of Lionel S. Beale.” Diagnostic cytopathology. Vol 9 No. 5 .

[11] Arthur I. Spriggs, "History of cytodiagnosis" Journal of Clinical Pathology, 1977, 30, 1091-1102.

[12] CIN; SZ Journal of Gynaecological Oncology 2009 Vol. 1 No. 1 Denny LA, Dept. Obst. Gynaec.

[13] William Boyd. A Textbook of Pathology. Structure and Function in disease. Seventh edition. 1961.

[14] Kottmeier HL. Evolution ettraitement des epitheliomas. Rev Franc Gynaecol 1961, 56, 821-825.

[15] Lozowski MS, Mishriki Y, Talebian I, Solitare G. The combined use of cytology and colposcopy in enhancing diagnostic accuracy of preclinical lesions of the uterine cervix. ActaCytol. 1982; 26(3): 285-291.

[16] Joe V. Meigs. The Vaginal Smear. The Journal of the American Medical Association,January 11, 1947, vol 133 , no. 2

[17] Ayre EJ. Selective Cytology Smear for Diagnosis of Cancer. Am. J. Obst. And Gynec. 1947; 53(4): 609-17.

[18] Papanicolaou GN. New Cancer Diagnosis. Proceedings of the 3rd race Betterment Conference. Battle Creek. Race Betterment Foundation. 1928; 528 534.

[19] Reagan JW, Seidemann IL and Sarcusa Y. Cellular morphology of carcinoma in situ \& dysplasia or atypical hyperplasia of uterine cervix. Cancer 1953;6:224-235.

[20] Stem E and Dixon WJ. Rate, stage, and patient age in cervical cancer; analysis of age specific disease rates for atypical hyperplasia, in situ cancer and invasive cancer in population. Cancer 1959;12:933-937.

[21] Moricard R. Importance of peri-orificial microbiopsies in early diagnosis of cancer of the uterine cervix and comparative statistical study of errors of vaginal cytology. Bull Fed SocGynecolObstet Lang Fr. $1955 ; 7(1): 28-9$

[22] Messerschmitt J. Value of vaginal cytology for the prognosis \& choice of treatment in cancers of the uterine cervix. AfrFrChir. 1957 May-Jun;15(3):281-6.

[23] De Alvarez RR, Figge DC, Brown DY. Long-range studies of the biologic behavior of the human uterine cervix. II.Histology, cytology, and clinical course of cervical disease. Am J Obstet Gynecol. 1957 Oct;74(4):769-87; discussion 787-91.

[24] Stoll P. The cytology of cancer of the uterine cervix. ActaUnioInt Contra Cancrum. 1958;14(4):314-8; discussion 319-20.

[25] Nolan JF, Kizziar JW, Davis FE. The cytology and treatment of carcinoma of the uterine cervix. Ariz Med. 1958 Sep;15(9):639-42.

[26] Koss LG. Exfoliative cytology of the uterine cervix and vagina. CA Cancer J Clin. 1960 Nov-Dec;10:18293.
[27] Richart RM. Evaluation of the true false negative rate in Cytology. Am. J. Obst andGynec. 1964; 89(6): 723726.

[28] Richart RM. Natural history of Cervical IntrapeithelialNeoplasia. ClinObstetGynecol 1968; 10:748-784.

[29] Yajima A, Watanabe M, Mori T, Yonemoto Y. The diagnostic accuracy of combined colposcopy, cytology, and target biopsy of carcinoma in situ of the uterine cervix. Tohoku J Exp Med. 1978 Oct;126(2):185-92.

[30] Valenzuela M, Cubillos J. Follow-up analysis and complementary study in patients with suspicious uterine cervix cytology. Rev ChilObstetGinecol. 1979;44(2):60-3.

[31] Schuhmann RA. Exfoliative cytology in the uterine cervix. Possibilities, limitations and clinical consequences of a morphologic method. Pathologe. $1981 \mathrm{Dec} ; 3(1): 25-38$.

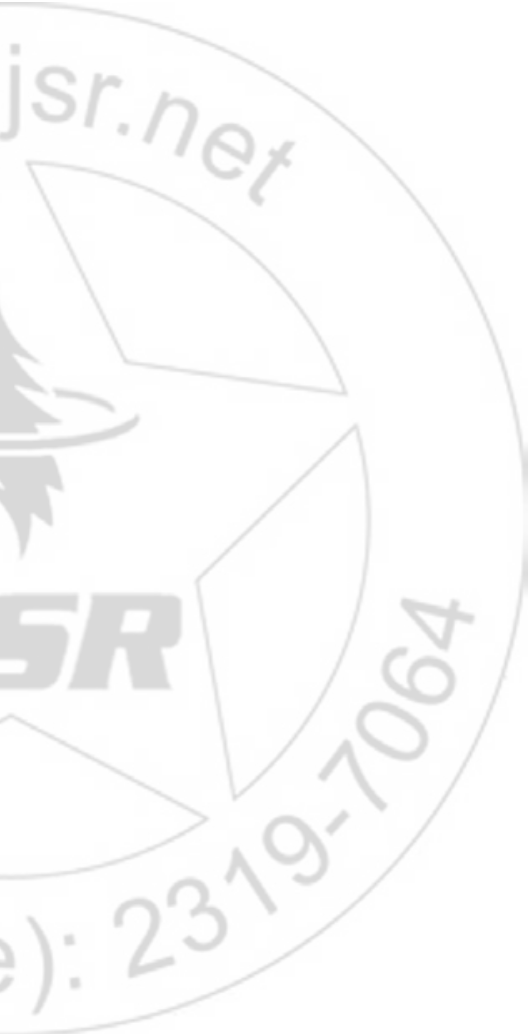

